\title{
DA BOCA VAZIA AO BEIJO NA BOCA
}

\section{FROM EMPTY MOUTH TO BEIJO NA BOCA}

\section{Débora Racy SOARES ${ }^{24}$}

RESUMO: O objetivo deste artigo é refletir sobre as artimanhas construtivas de Beijo na boca que oscilam entre o velar e o revelar e afetam a configuração cindida do sujeito lírico. A forma-fragmento, os deslocamentos - irônicos e temporais correspondem à passagem do interdito pela linguagem. Nesse sentido, recuperamos a idéia de trauma e de catástrofe para pensar sobre a aparência estética, seu jogo de representações e as formas de dizer o silêncio.

PALAVRAS-CHAVE: Poesia brasileira; Cacaso; Beijo na boca; Trauma; Catástrofe.

ABSTRACT: The purpose of this article is to reflect on the constructive tricks of Beijo na boca that wave between hiding and showing, affecting the split configuration of the lyric subject. Fragmentary form, dislocations - both ironic and related to time - correspond to the passage of interdict through language. Accordingly, we retrieve the idea of trauma and catastrophe to think about the aesthetic appearance, its role-playing games and the ways to say about the silence. KEYWORDS: Brazilian poetry; Cacaso; Beijo na boca; Trauma; Catastrophe.

\footnotetext{
${ }^{24}$ Doutoranda do Programa de Pós-Graduação em Teoria e História Literária (Bolsista FAPESP) Instituto de Estudos da Linguagem - Universidade Estadual de Campinas (UNICAMP) - CEP 13083-970 - Campinas - SP - Brasil - E-mail: debora_racy@yahoo.com.br
} 
A aparência poética é jogo de representações.

Schlegel

À primeira vista, Beijo na boca (1975), escrito por Antônio Carlos Ferreira de Brito (1944-1987) - doravante Cacaso - é um livrinho despretensioso, recheado de pequenos poemas de amor. À segunda visada, entretanto, começamos a perceber que o livro oculta mais do que revela. Ou, deveríamos dizer, revela mais do que oculta? De qualquer forma, Cacaso parte desta tensão - espécie de artimanha construtiva - entre o velar e o revelar para sustentar uma lírica que, pour cause, traz para o cerne dos poemas - através da configuração do sujeito lírico - conflitos de difícil resolução.

Assim, ancorada entre o desejo de dizer e sua impossibilidade fundante, essa lírica - que elege a temática amorosa para tocar em questões que a transcendem - tãosomente (re)vela a "inadequação entre aquilo que está sendo dito e o que se pretend(e) dizer" (BRITO, 1997, p. 284).

No entanto, o que "se pretend(e) dizer"? Seria esta intenção da ordem do indizível, do intraduzível em palavras? E ainda: como "o que se pretend(e) dizer" se dá a ver no poema, concretizando a passagem da intenção ao ato? Se o que é da ordem do indizível também atinge a linguagem poética, pois ali está, a ponto de se deixar perceber, então o indizível, embora a priori arredio à linguagem, não escapa à percepção. É certo: “o que se pretend(e) dizer” acaba sendo dito pelo poema. Dessa maneira, se o que se quer dizer parece interdito pelo que se pode dizer, a "linguagem conserva o indizível, dizendo-o, ou seja, colhendo-o na sua negatividade." (AGAMBEN, 2006, p.28). Por isso, ao manter o indizível no "próprio coração da palavra”, a linguagem hospeda o silêncio (AGAMBEN, 2006, p.28).

Uma das maneiras de sinalizar a permanência do indizível na linguagem e, ao mesmo tempo, operar a passagem da intenção ao ato é através da forma poética fragmentária. Se a forma é indissociável do que se diz, a eleição do fragmento para dizer, além de reafirmar a precariedade de todo dizer, traz para a cena da escrita a ordem do não-dito. $\mathrm{O}$ fragmento convoca ainda a ideia do work in progress que, à maneira da "vontade hermenêutica sub-versiva e inconclusiva", deixa entrever certo "pudor do definitivo", certo "temor da conclusão" (BARRENTO, 1999, p.11). 
Ademais, ao introduzir o conteúdo aos poucos e em frações, a forma fragmentária reafirma a incompletude da experiência e a falta de transparência do conhecimento. Logo, além de problematizar o conceito de verdade, este tipo de construção estética acaba inaugurando, no cerne dos poemas, uma espécie de crise da verdade. Crise que rebate na instabilidade do sujeito lírico, dividido entre sucessivos estranhamentos, com problemas de identidade e de identificação com e de seus amores, namoradas. Amores e namoradas que, diga-se de passagem, sintomaticamente não são nomeados. Essa constatação, por si só, já seria impeditiva para a concretização do amor, pois se "só existe amor por um nome", é imprescindível que esse nome seja explicitado, "pronunciado" (LACAN, 2005, p.366). Assim sendo, embora se proponha amorosamente - mediante sua temática - essa lírica só faz alegorizar ausências, através da "falta de quem nos olhe" (BRITO, 2002, p.161), "daquele amor que nunca tive" (BRITO, 2000, p.53). Se, por um lado, ela sinaliza a hiância constitutiva do sujeito, por outro enfatiza a presença da ausência no cerne dos poemas. De certa forma, o sujeito só pode ser à medida que não é, isto é, à medida que existe enquanto desejo, enquanto ser em falta, falta a ser. Esta consciência da carência, esta explicitação da falta que constitui a subjetividade do sujeito lírico, não é nada reconfortante. Pelo contrário, seu reconhecimento conduz à angustiante sensação de estranhamento.

A configuração cindida do sujeito lírico seria, portanto, a outra maneira de realizar aquela passagem da intenção ao ato. Dividido entre seus "dois amores" e com o "coração em frangalhos", este sujeito - "parte" que se "reparte" - sofre com a dificuldade, impossibilidade até, de afirmar sua subjetividade (BRITO, 2000, p.20 e p.22). Se esta dificuldade repercute na desarticulação do discurso, também conduz, no limite, à própria decomposição subjetiva do ser em "suave dispersão na inexistência". (BRITO, 2000, p. 56). Por isso, não causa espanto perceber que, à medida que avançamos na leitura de Beijo na boca, presenciamos o estiolamento do sujeito lírico. Os conflitos internos que experimenta são tantos e tamanhos - seja em relação às expectativas do outro, figurado pelas namoradas e ex-namoradas - seja em relação a si próprio - "já não recordo meu nome" - que só poderiam conduzir à radical dissociação de sua subjetividade (BRITO, 2000, p.56). "Não recordar" o próprio "nome" significa não saber mais quem se é, pois se o nome identifica, sua ausência expõe a alienação que 
reifica e desumaniza, além de sinalizar certa amnésia sintomática, em consonância com a violência conjuntural.

Se esta amnésia, na verdade, não é bem uma amnésia, isto é, não consiste em um total esquecimento ou apagamento da memória, dado que o sujeito insiste em afirmar e confirmar, ainda que pela ausência, sua certeza, sua falta de nome, a violência, por outro lado, é evidente. Nesse ponto, perpassado pela experiência da dor, este sujeito estilhaçado, ao revelar seus traumas mais radicais também expõe as dores de um "país traumatizado", cuja história, desde o período da colonização, tem sido marcada pela "injustiça" e pela "iniqüidade" (RIBEIRO, 1999, p.10-11). De fato, enquanto este sujeito lírico que, sublinhamos, fala no plural, for incapaz de elaborar suas dores, estará fadado à sua compulsão repetitiva.

Assim, encontramos um sujeito em franco desajuste com o outro, com o mundo, a experimentar a patente e patética impossibilidade de (re)conciliação que deságua no lirismo da desilusão, no qual se ancora este Beijo na boca. Em tempo: gostaríamos de deixar registrado que este outro - pronome indefinido que tudo acolhe - refere-se também ao país em que se vive, ao lar, ao familiar (Heim). Dadas as ambiguidades semânticas que se acumulam em Beijo na boca, essa possibilidade de leitura é pertinente, como veremos mais abaixo. Esclarecemos, ainda, que o adjetivo patético, em sentido etimológico, remete às paixões da alma que nos fazem sofrer, como se fossem doenças. Embora esteja associado à passividade, o pathos - em sentido aristotélico também incorpora a atividade, a ação. Portanto, a capacidade de agir, no sentido de "poder-tornar-se", é inerente ao sujeito que sofre uma ação, o paciente (LEBRUN, 1995, p.18). Logo, o ser que padece é indeterminado por natureza, pois sua característica principal é "ser movido", ser “mutável”, sujeito à paixão (LEBRUN, 1995, p.18). Podemos pensar que agir, no contexto da década de setenta, significa resistir, não se deixar "paralisar pelos esquemas paralisantes" (BRITO, 1997, p.54). Se a "paixão é sempre provocada pela presença ou imagem de algo que me leva a reagir", então, o ser que sofre é o ser que, de alguma forma, re(age), resiste e "pode-tornar-se" (LEBRUN, 1995, p.18). Em consequência, a paixão "é um sinal” de que se "vive na dependência permanente do Outro" (LEBRUN, 1995, p.18).

Em resumo: ambas as estratégias construtivas mencionadas - a forma poética fragmentária e a cisão do sujeito lírico - são modos de validar o conteúdo latente, 
expondo "o que se preten(de) dizer" em versos. Nesse sentido, a escolha temática amorosa também participa destas estratégias mencionadas, à medida que funciona como um filtro ou "isca" poderosa, capaz de ludibriar o leitor (BRITO, 1997, p.283). Explique-se: o leitor moderno, isto é, participativo, precisa "morder" a "isca" para ter “acesso àquilo que as aparências não revelam" (BRITO, 1997, p. 283). Em tempo: "morder" a "isca" significa, em sentido figurado, perceber nas entrelinhas, entender rapidamente e, não, como pode parecer, se deixar fisgar, enganar, embora essa possibilidade não esteja totalmente excluída.

Por conseguinte, se a "linguagem está cifrada", precisamos, através da leitura, "decifrá-la" (BRITO, 1997, p.284). Imperativo, portanto, é que se "decifre a aparência amável" e se "leve o jogo a sério" (SCHLEGEL, 1997, p.158). No entanto, de acordo com a hermenêutica moderna, perdemos a "chave para a leitura desta escrita cifrada do mundo" (SELIGMANN-SILVA, 1999, p.30) Em outras palavras: não há mais um "sentido transcendental" que garanta o significado, dado que ele sempre nos "escapa" (SELIGMANN-SILVA, 1999, p.30). Assim, restaria ao leitor a incompleta e melancólica tarefa de ler, "traduzi(ir) e altera(r)" os sentidos "multiplamente" (SCHLEGEL, 1997, p.98).

Partindo deste pressuposto, poderíamos pensar que a linguagem poética guarda um segredo que só poderia vir à tona no encontro com outra subjetividade leitora. Do segredo, na verdade, só temos os resquícios, pois ele é, por definição, da ordem do interdito. No entanto, se a "linguagem pode perfeitamente nomear aquilo de que não pode falar", então, este segredo pode ser compartilhado (AGAMBEN, 1999, p.104). A operação de leitura, por sua vez, menos do que se contentar em acolher a "aparência", aceitando o "jogo de representações", pode contribuir para problematizar este "jogo" e "colocar em palavras o inominável" (SCHLEGEL, 1997, p.61; ABRAHAM; TÖROK, 1995, p.239). Nesse sentido, a leitura pode resgatar e reafirmar sua dimensão ética, à medida que colabora para explicitar a violência inerente ao inominável. Quando as "cicatrizes" não podem ser "transfer(idas)", ficamos impossibilitados de sentir na própria pele as marcas do sofrimento alheio (BRITO, 2000, p.54). No entanto, ainda podemos escutar e testemunhar a violência da história através da dor que perpassa o sujeito lírico. 
Dessa forma, se Cacaso é poeta moderno, isto é, "sentimental", de acordo com as categorias estabelecidas por Schiller, isto é, se precisa lidar com "representações e sensações conflitantes", também exige um leitor que não seja ingênuo (SCHILLER, 1991, p.64). E ingênuo, de acordo com Cacaso, e não com Schiller, seria aquele leitor “distraído ou superficial", "vítima d(as) aparência(as) enganosas" dos poemas (BRITO, 1997, p.284). Assim, os poemas, à semelhança de uma "casca", ainda que fiquem "marcad(os) por aquilo que el(es) abriga(m), aquilo que é ocultado por el(es) nel(es) se revela" (ABRAHAM; TÖROK, 1995, p.192).

A esta altura, gostaríamos de retomar a ideia de segredo, a partir do ponto de vista da psicanálise, lembrando que ela pode nos auxiliar, já que um de seus maiores temas é a "oposição entre o aparente e o escondido, o manifesto e o latente, os disfarces e o desejo" (ABRAHAM; TÖROK, 1995, p.238). É importante entender que a "realidade metapsicológica" do segredo não se dissocia da "realidade do mundo exterior", tanto que a "negação" daquela implica na "recusa" desta (ABRAHAM; TÖROK, 1995, p.237-238). Dessa perspectiva, se a "realidade" é sempre "realidade a escamotear", ela é o próprio "lugar em que o segredo está escondido" (ABRAHAM; TÖROK, 1995, p.237). Assim sendo, o segredo abriga o que é "recusado, mascarado, denegado" (ABRAHAM; TÖROK, 1995, p.237). Posto de outra forma: o segredo encerra o recalcado que se revela nas palavras como sintoma. Nesse sentido, podemos pensar que os poemas de Beijo na boca são sintomáticos, à medida que abrigam o segredo de uma "realidade" que "nasce pela exigência de permanecer escondida, vergonhosa" (ABRAHAM; TÖROK, 1995, p. 238). É como se "as palavras do sujeito" tivessem sido "atingidas por uma catástrofe que as pôs fora de circuito", tornando-as indizíveis (ABRAHAM; TÖROK, 1995, p. 238). Por outro lado, quando o sujeito lírico enuncia nos poemas seus "neo-românticos segredos", deles se liberta (BRITO, 2000, p.31). Desse modo, a escrita pode ser encarada como um esforço terapêutico, capaz de conduzir à elaboração, à assimilação do "que não cabe nas palavras" (ABRAHAM; TÖROK, 1995, p. 239). É aí, neste ponto, que o "indizível” muda de signo, tornando-se “desejo recalcado" de "não dizer" e se diz, se enuncia através de seus "desvios", de “suas mil maneiras de se simbolizar" (ABRAHAM; TÖROK, 1995, p. 242).

A ideia de catástrofe, mencionada há pouco, está relacionada à questão da representação, à medida que a problematiza. Catástrofe deriva do grego e, em sentido 
literal, quer dizer "virada para baixo", podendo também significar "desabamento ou desastre". Sua definição remete a "um evento que provoca um trauma, um "ferimento", (NESTROVSKI; SELIGMANN-SILVA, 2000, p.8; aspas dos autores). O conceito de trauma, do ponto de vista da psicanálise freudiana, remete a acontecimentos que não podem ser assimilados enquanto ocorrem e, tampouco posteriormente, a não ser de modo precário. Pelo fato de estes acontecimentos não terem sido inteiramente compreendidos, tendem a retornar, de forma insistente, através, por exemplo, da repetição.

De certa forma, observar o que se repete nos versos de Beijo na boca é uma das maneiras de descobrir o que escapa à representação. Escapa e, paradoxalmente, está lá representado, dado que o sujeito lírico insiste em falar sobre o interdito. Assim, é possível entrever os "traumas psíquicos" desse sujeito, atentando para a "cena traumática" configurada nos poemas (FREUD, 1978, p.6). Vejamos o poema de abertura de Beijo na boca:

E com vocês a modernidade

Meu verso é profundamente romântico.

Choram cavaquinhos luares se derramam e vai por aí a longa sombra de rumores e ciganos.

Ai que saudade que tenho de meus negros verdes anos!

(BRITO, 2000, p.11).

Operar por deslocamentos ou desvios é um dos procedimentos estéticos mais caros a Cacaso. Este tipo de recurso é eficiente, pois mobiliza a ironia que emprega os contrastes, as incongruências, com efeito zombeteiro. Lembramos que zombar, em sentido figurado, significa escapar por meio de artimanhas, burlar. Além disso, a ironia promove a instabilidade semântica, propícia para fazer os sentidos deslizarem. Assim, o deslocamento temporal sugerido, no primeiro verso, só faz contrariar as intenções anunciadas pelo título. 
Através da ironia, o que é posto tão-somente contradiz o que é pressuposto. Atente-se para o efeito irônico decorrente da utilização do advérbio "profundamente". Na tensão entre o que é prometido - "a modernidade" - e o que aparece no corpo do poema - "versos profundamente romântico(s)" - os sentidos vacilam. Será o caso de questionarmos se apenas o primeiro verso é "profundamente romântico" e os demais, modernos? Pois "meu verso" pode se referir tanto ao primeiro verso do poema, como aos demais que o compõem. Em sentido extensivo, pode remeter também à composição literária, à poesia. Esta indeterminação, provocada pelo desvio semântico, redunda na estratégica tentativa de descontextualização por despistamento.

Outra maneira de utilizar os deslocamentos é não chamando as coisas pelos nomes, isto é, não dando "nome aos bois", pois eles "nunca [...] estiveram com os nomes tão impróprios e trocados" (BRITO, 1997, p.228). Em meio aos "Problemas de nomenclatura", o poeta revela que "o nome" da "primeira namorada" "dançou", pois "Lá em casa é assim": "o meu amor diz que me ama/ mas jamais me dá um beijo" (BRITO, 2000, p.14-15). Logo, o descompasso entre a essência e a aparência fecunda poemas cujos "estilos" estão "trocados", pois o desencontro é marcado e o "Ciclo vicioso" (BRITO, 2000, p. 17).

Quanto à cena do poema acima, os versos modernos sugerem uma atmosfera aparentemente romântica, seja através da presença da noite ou da utilização da prosopopeia - "Choram cavaquinhos luares se derramam" - como recurso estilístico. Em outras palavras: o estado d'alma do sujeito lírico é correlato à configuração da paisagem, pois interioridade e exterioridade se confundem, como num "Jogo de reflexos". A atmosfera sombria é sinalizada pelos "luares" que, se mantida a ambiguidade do verbo derramar, podem tanto verter lágrimas, como estarem tomados de paixão ou dispersos, espalhados. A ideia de que os "luares" testemunham pessoas que foram postas em debandada também cabe dentro do significado do verbo derramar. Quanto à natureza - sugerida pela presença de "luares" - menos do que locus amoenus, refúgio edênico, à maneira romântica, figura como locus horribilis, incapaz de confortar o sujeito lírico. Aliás, à medida que o livro avança, vamos percebendo que o cenário traumático responde pela desarticulação do poema, do sujeito, clivado em "part(es)" que se "repart(em)" (BRITO, 2000, p.22). Se o poeta romântico era o vate, o decifrador da natureza par excellence, ao poeta moderno, atado à sua trágica existência, resta a 
constatação de que não há nada a decifrar, pois o "enigma" não é "mais que aparência" e se "refere apenas à linguagem e à sua(s) ambigüidade(s)" (AGAMBEN, 1999, p.106).

Novamente a indeterminação gera ambiguidades semânticas produtivas do ponto de vista poético. Por quem "choram" os "cavaquinhos" quando emitem sons plangentes? Por quem "luares se derramam", manifestando efusivamente seus sentimentos? O profundo sentimento de tristeza - sugerido pela escolha dos verbos líquidos chorar e derramar - leva a crer que o sujeito lírico suspire de dor, não de amor. “A longa sombra de rumores e ciganos" traz a questão do exílio para o cerne do poema. Os "negros verdes anos", se podem remeter à infância, também recolocam o poema no contexto de produção, anulando o deslocamento temporal sugerido no primeiro verso. Em outro momento do livro, em “Aos pés! Da musa”, o sujeito lírico revela: "ainda somos crianças" e "assim voam verdes anos" (BRITO, 2000, p.31).

Ao longo deste Beijo na boca, a reiteração de determinadas expressões - "negros verdes anos", "história" de "fatalidade", "pensamento" que "sangr(a)", poesia "contra o tempo e o momento" - deixa entrever os impactos de eventos sentidos como traumáticos pelo sujeito lírico (BRITO, 2000, p.26-27, 36). A dificuldade em nomear, portanto, em representar, confirmada pela fragmentação da forma, pela indeterminação geradora de ambiguidades, pela ironia que promove desvios semânticos, valida uma experiência poético-existencial de dimensões catastróficas. O poema, portanto, é uma "quebra do silêncio", mas também uma "forma d(e) (o) poeta silenciar" (BRITO, 1997, p.247).

Encaminhando-nos para a conclusão, gostaríamos de recuperar um poema que está em Segunda classe, livro escrito no mesmo ano de Beijo na boca (1975), por Cacaso e Luís Olavo Fontes. No poema “Lar doce lar”, Cacaso diz:

Minha pátria é minha infância:

Por isso vivo no exílio

(BRITO, 2002, p.53).

É interessante lembrar que a infância se relaciona ao período de aquisição da linguagem. Por isso, a palavra "infância", derivada do latim infans, significa aquele que não fala. Em Beijo na boca, o sujeito lírico afirma ser "ainda criança”, sinalizando sua 
dificuldade ou impossibilidade de falar. De certa forma, Beijo na boca configura uma poética de balbucios que hesita em se pronunciar e promove confusões (desvios, deslocamentos) para enunciar os traumas do sujeito lírico.

Se pátria é sinônimo de infância, então, carrega toda a conotação inerente ao infans. Logo, pátria = infância = sem fala. $\mathrm{O}$ poeta figura agora como exilado, expatriado, fora da pátria. Mais uma vez, pelo deslocamento irônico, os sentidos estão em conflito. O poeta só pode falar na condição de expatriado e, para isso, precisa assumir a figura do exilado. O exilado, por definição, é o sujeito que incorporou a dimensão da perda, seja do país, da linguagem ou da própria identidade. Nesse sentido, o sujeito expatriado experimenta a sensação de não-reconhecimento, de não-pertença frente ao país estranho, estrangeiro. No entanto, em "Lar doce lar", o sujeito lírico - exilado em sua própria pátria-linguagem - precisa lidar com o Das Unheimliche freudiano. Assim, a travessia do Heim - do lar, do familiar, do país natal - para o Unheim - desconhecido, não-familiar - talvez possa ser acompanhada por outra (ultra)passagem correlata que conduz da ausência da fala à fala em ausência. Se a ausência da fala corresponde à boca vazia, a fala em ausência convoca a boca, cheia de palavras, a compartilhar a linguagem no Beijo.

\section{REFERÊNCIAS}

ABRAHAM, N.; TÖROK, M. A casca e o núcleo. Tradução Maria José R. Faria Coracini. São Paulo: Escuta, 1995.

AGAMBEN, G. A linguagem e a morte: um seminário sobre o lugar da negatividade. Tradução Henrique Burigo. Belo Horizonte: UFMG, 2006.

Ideia da prosa. Tradução João Barrento. Lisboa: Cotovia, 1999.

BARRENTO, J. Prefácio. In: AGAMBEN, G. Ideia da prosa. Tradução João Barrento. Lisboa: Cotovia, 1999. p.9-11.

BRITO, A. C. F. Lero-lero. Rio de Janeiro: 7Letras; São Paulo: Cosac \& Naify, 2002. Beijo na boca. 2.ed. Rio de Janeiro: 7Letras, 2000.

Não quero prosa. Organização Vilma Arêas. Campinas, SP: UNICAMP; Rio de Janeiro: UFRJ, 1997. 
LACAN, J. O seminário. Tradução Vera Ribeiro. Rio de Janeiro: J. Zahar, 2005 (Livro 10: A angústia).

LEBRUN, G. O conceito de paixão. In: NOVAES, A. (Org.). Os sentidos da paixão. São Paulo: Companhia das Letras, 1995. p.17-35.

NESTROVSKI, A.; SELIGMANN-SILVA, M. Apresentação. In: Catástrofe e representação. São Paulo: Escuta, 2000. p.7-12.

FREUD, S. Cinco lições de psicanálise. Tradução Durval Marcondes e J. Barbosa Correa. São Paulo: Abril Cultural, 1978.

RIBEIRO, R. J. A dor e a injustiça. In: COSTA, J. F. Razões públicas, emoções privadas. Rio de Janeiro: Rocco, 1999. p.7-12.

SCHILLER, F. Poesia ingênua e sentimental. Tradução, apresentação e notas Márcio Suzuki. São Paulo: Iluminuras, 1991.

SCHLEGEL, F. O dialeto dos fragmentos. Tradução Márcio Suzuki. São Paulo: Iluminuras, 1997.

SELIGMANN-SILVA, M. Ler o livro do mundo - Walter Benjamin: Romantismo e crítica poética. São Paulo: Iluminuras/FAPESP, 1999.

Artigo recebido em 10/04/2010. Aceito para publicação em 26/05/2010. 